\title{
Not all bullshit pondered is tossed: Reflection decreases receptivity to some types of misinformation but not others
}

\author{
Shane Littrell, Ethan A. Meyers, \& Jonathan A. Fugelsang \\ Department of Psychology, University of Waterloo, Waterloo, ON, Canada
}

Draft version: $2 / 25 / 2022$. This is an unpublished working paper that is currently undergoing peer review. Contents may change prior to publication.

Word count: 9216 (excluding title page, abstract, tables and legends, and references)

All data files, materials, and pre-registration information can be found here: $\underline{\text { https://osf.io/2tndf/ }}$

Correspondence concerning this article should be addressed to Shane Littrell, Department of Psychology, University of Waterloo, Waterloo, ON, Canada N2L 3G1

CONTACT: Shane Littrell, sslittrell@uwaterloo.ca 


\begin{abstract}
Receptivity to misinformation is often attributed to reduced engagement in reflective thinking. However, much of the evidence for this association is correlational and lacks experimental support. Across four studies $(N=818)$, we present evidence that engaging in guided, explanatory reflection reduces receptivity to pseudo-profound bullshit but not scientific bullshit or fake news. We also found robust effects of source credibility, in that ratings for pseudo-profound and scientific bullshit attributed to authoritative sources were significantly inflated compared to bullshit attributed to anonymous sources. However, these effects were markedly weaker for accuracy ratings of fake news headlines. These findings provide initial evidence that an illusion of understanding may underlie receptivity to some types of misinformation but not others and that the appeal of misinformation spread by perceived experts may be largely immune to the putative benefits of interventions that rely solely on reflective thinking. Taken together, our results suggest that while encouraging the public to be more reflective can certainly be helpful as a general rule, the effectiveness of this strategy in reducing the persuasiveness of misinformation is limited by the type of misinformation one is exposed to as well as the perceived credibility of the source spreading it.
\end{abstract}

Key words: bullshit receptivity, misinformation, illusion of explanatory depth, fake news, source credibility, cognitive reflection 


\section{Introduction}

"Illusion is needed to disguise the emptiness within." - often attributed to Arthur Erickson

Misleading information - often referred to as bullshit - comes in many forms, including pseudoscientific "health and wellness bullshit" peddled by influential celebrities (Belluz, 2018; Fox, 2014), meaningless pseudo-profound “deepities” (Pennycook et al., 2015), empty and confusing business jargon (Spicer, 2020), and fake news and COVID-19 misinformation shared on social media (Mastrangelo, 2021; Pennycook et al., 2021). While some forms of bullshit are arguably more harmful than others (e.g., misleading claims regarding "miracle cures" for serious diseases), concern over the spread of misleading information in general and awareness of the often detrimental consequences of its influence has grown in recent years. Indeed, public surveys show that $81 \%$ of US adults view misinformation, especially online, as a major problem (The Pearson Institute et al., 2021) while $88 \%$ believe that it has led many people to be confused about basic facts (Pew Research Center, 2016). Critically, a recent analysis showed that fake news spreads on Twitter much more quickly than accurate information, a finding reflected in the folk notion that "falsehood flies, while the truth comes limping after it" (Vosoughi et al., 2018). In light of these growing concerns, efforts to diminish the persuasiveness of misinformation have become increasingly important. In the present work, we sought to determine the utility of using a guided reflection-based intervention task to reduce people's susceptibility to various forms of misinformation.

\section{Receptivity to misleading information}

Though misinformation is not a new phenomenon, researchers have recently devoted 
more attention to understanding the cognitive and social factors associated with its spread, as well as devising interventions that might curb misinformation's influence (e.g., Čavojová et al., 2019; Littrell et al., 2021; Pennycook et al., 2021). Much of this work focuses on individual differences in receptivity to bullshit, one of the most common forms of misinformation (Frankfurt, 1986). Bullshit receptivity refers to a proclivity for giving inflated positive evaluations to misleading information for qualities such as its profoundness, truthfulness, or persuasiveness (Littrell \& Fugelsang, 2021; Pennycook et al., 2015). In technical terms, bullshit is information constructed with a carefree indifference for conveying truth, accuracy, clarity, or meaning that is often used to impress, persuade, or otherwise mislead others (Littrell \& Fugelsang, 2021). Various measures of bullshit receptivity task participants with evaluating qualities such as truthfulness, profoundness, or accuracy of real statements (e.g., "Towering genius disdains a beaten path. It seeks regions hitherto unexplored," Abraham Lincoln) and statements randomly generated by a computer algorithm that are devoid of any actual intention to communicate truth, clarity, or meaning (e.g., "The unpredictable belongs to an abundance of external reality“). Bullshit receptivity is then measured by comparing a person's ratings of the computer generated statements to their ratings of the real statements (Evans et al., 2020; Pennycook et al., 2015). Greater bullshit receptivity is associated with lower analytic thinking ability, verbal intelligence, and numeracy as well as higher levels of conspiratorial ideation, ontological confusions, and engagement in persuasive bullshitting (Čavojová et al., 2019; Littrell et al., 2021; Pennycook et al., 2015).

To date, the scientific study of bullshit has focused primarily on examining the associations between bullshit receptivity and various aspects of analytic thinking, such as the role cognitive reflection plays in a person's resistance to bullshit's influence. Much of this work is 
correlational, resting on the negative bivariate associations between scores on analytic thinking measures such as the Cognitive Reflection Test (CRT) and scores on the Bullshit Receptivity Scale (Frederick, 2015; Pennycook et al., 2015). As CRT scores are often interpreted as an indicator of propensity to engage in reflective thinking over faster, lower-effort intuition, this negative correlation has been leveraged as evidence that receptivity to various types of bullshit results largely (but not completely) from a failure to engage in cognitive reflection when evaluating misleading information (e.g., Čavojová et al., 2019; Pennycook \& Rand, 2020). If true, then an intervention which actively increases engagement in reflection should reduce receptivity to misinformation.

However, we are unaware of any experimental evidence directly testing this (or comparable) hypotheses and recent empirical work has challenged some of its underlying assumptions. For example, recent studies have found that many people correctly solve CRT items intuitively ("smart intuition") rather than reflectively, suggesting that CRT scores may not be a reliable indicator of engagement in reflective thinking (Bago \& De Neys, 2019; Raoelison et al., 2020). Additionally, higher bullshit receptivity in some people may not result from intuitive thinking, but instead from engaging in suboptimal or otherwise faulty reflective thinking, such as rationalization (Littrell \& Fugelsang, 2021). Moreover, reflective thinking may actually increase, rather than decrease, endorsement of certain conspiracy theories for some people (Vitriol \& Marsh, 2021). These conflicting findings lead to at least two compatible hypotheses: 1) some people are more receptive to bullshit because they avoid engaging in cognitive reflection, and; 2) some people are more receptive to bullshit because they engage in poor/faulty forms of cognitive reflection. Regardless of which account is more accurate, both hypotheses suggest that an intervention task that encourages engagement in guided, detail-oriented reflection may help 
attenuate an individual's receptivity to bullshit.

\section{Epistemic overconfidence and the illusion of explanatory depth}

Receptivity to misinformation is positively associated with various types of overconfidence (e.g., Salovich \& Rapp, 2021). For example, those who are most receptive to pseudo-profound bullshit and fake news overestimate their ability to detect it and exhibit a "bullshit blind spot" by believing their detection abilities are better than those of the average person (Littrell \& Fugelsang, 2021, Lyons et al., 2021). Additionally, receptivity to pseudoprofound bullshit is positively related to a person's confidence that they have knowledge of nonexistent concepts, known as overclaiming (Pennycook \& Rand, 2020). Such confidence in having impossible-to-hold knowledge, as well as lacking awareness of the limits of one's own knowledge, bears striking resemblance to the illusion of explanatory depth (also known as an illusion of understanding), a type of epistemic overconfidence that reflects a person's belief that they understand a concept or phenomenon (e.g., how a zipper works) to a greater degree than they really do (Rozenblit \& Keil, 2002). The illusion is demonstrated by measuring the extent to which a person's inflated subjective estimate of their understanding of some concept or phenomenon decreases after trying to explain how that concept or phenomenon works.

In the classic paradigm, a person estimates their level of understanding of some phenomenon twice. In between the two estimates, the person is asked to explain, in as much detail as possible, the complex casual chain responsible for how that phenomenon works (e.g., how a zipper attaches two pieces of fabric together). Attempting to generate these explanations requires engagement in a type of detail-oriented reflective thinking from which a person may be made aware of previously unrealized gaps in their knowledge. This realization can be an 
epistemically humbling experience for some people (Meyers et al., 2020; Rozenblit \& Keil, 2002) and often results in a reduced (and arguably more accurate) self-assessment of knowledge immediately after the explanation task.

Although early examinations of the illusion of explanatory depth (e.g., Mills \& Keil, 2004; Rozenblit \& Keil, 2002) largely focused on participants' knowledge of mechanical operations (e.g., how a helicopter flies), similar results have been found for other knowledge domains. For example, an illusion of understanding has been exposed for knowledge of economic and political issues (Fernbach et al., 2013; Meyers et al., 2020) as well as knowledge of natural phenomenon such as how snow forms and what causes earthquakes (Rozenblit \& Keil, 2002). Given these findings, as well as bullshit receptivity's positive associations with different types of overconfidence and negative associations with analytic thinking (e.g., Littrell \& Fugelsang, 2021; Littrell et al., 2021; Pennycook \& Rand, 2020), it is reasonable to hypothesize that an illusion of understanding may also underlie receptivity to various types of misinformation. Therefore, the process of exposing an illusion of understanding may be a fitting candidate for an intervention task that encourages engagement in deeper reflection to ameliorate an individual's receptivity to bullshit.

\section{Present investigation}

Receptivity to misinformation is positively related to several common forms of overconfidence and may result from either faulty, error-prone rationalizing or failing to engage in sufficient reflective thinking at all (Littrell \& Fugelsang, 2021; Littrell et al., 2021; Lyons et al., 2021; Pennycook \& Rand, 2020; Salovich \& Rapp, 2021). Additionally, research has consistently shown that an illusion of understanding - a type of epistemic overconfidence - can 
be exposed and attenuated by engaging in a form of guided, explanatory reflection (e.g., Meyers et al., 2020; Rozenblit \& Keil, 2002; Vitriol \& Marsh, 2018). However, the bulk of the evidence linking misinformation receptivity to reflective thinking is correlational and experimental examination of these putative associations is largely absent from the literature. Thus, it remains unclear to what extent receptivity to certain types of misinformation, such as bullshit, is supported by an illusion of understanding and whether engaging in an explanation-generation task could aid in exposing and reducing this receptivity. Here we report four experiments $(N=$ 818) that shed light on the relationship between an illusion of understanding and receptivity to misleading information (pseudo-profound bullshit, scientific bullshit, and fake news) and the utility of using guided, detail-oriented reflection to combat susceptibility to believing bullshit. All experiments reported here received committee approval from the Office of Research Ethics at the University of Waterloo located in Waterloo, Ontario, Canada.

\section{Experiment 1}

In Study 1, we offer an initial investigation into whether profoundness ratings for pseudoprofound bullshit are supported by an illusion of understanding. To test this, we used a pre-post design by adapting a standard illusion of explanatory depth paradigm to examine whether engaging in explanatory reflection decreases the perceived profoundness of pseudo-profound statements across a within-subjects manipulation.

\section{Method}

\section{Participants}

This study was pre-registered. All data files, materials, and pre-registration information can be found here: https://osf.io/2tndf/. We collected responses from 159 undergraduate 
psychology students (38 male, 121 female, $\mathrm{M}_{\text {age }}=20.60, \mathrm{MIN}_{\text {age }}=17, \mathrm{MAX}_{\text {age }}=50$ ) at the University of Waterloo who participated in the roughly 20 -minute survey for course credit. ${ }^{1}$

\section{Procedure}

The study design was a 2 Statement Type (pseudo-profound vs. motivational) by 2 Time (pre-reflection vs. post-reflection) mixed design. Statement Type was the between-subjects factor while Time was the within-subjects factor. After reading an informed consent form, those who agreed to participate answered three demographic questions (i.e., age, biological sex, and level of education).

Participants rated the profoundness of 10 items from the Bullshit Receptivity Scale (BSR; Pennycook et al., 2015), presented on screen one at a time in a randomized order, using a 5-point scale from 1 ("not at all profound") to 5 ("very profound"). Five of these statements were randomly generated by an algorithm from abstract pseudo-profound buzzwords (e.g., "We are in the midst of a high-frequency blossoming of interconnectedness that will give us access to the quantum soup itself') in a way that is syntactically correct but semantically meaningless. The remaining 5 statements were popular motivational quotes taken from various websites (e.g., “A river cuts through a rock, not because of its power but its persistence"). Mean ratings for both pseudo-profound and motivational statements are labelled pre-reflection ratings.

Participants rated all 10 statements twice. However, before the second ratings were given, participants read the following instructions which were adapted from a standard illusion of explanatory depth paradigm (Meyers et al., 2019; Rozenblit \& Keil, 2002): “As best you can,

\footnotetext{
${ }^{1}$ Our pre-registered sample size goal was 50 participants. However, we collected data during the first full semester in which pandemic restrictions were in place (Fall 2020), which limited the number of studies in which students could participate. Given these special circumstances, we increased our data collection time period as a courtesy to the student participant pool. This resulted in our sample size exceeding our pre-registered goal.
} 
please describe in detail why the quote below is profound or is not profound. That is, give your best explanation as to what precisely it is about the quote that causes you to feel that it is a profound statement or is not a profound statement." Each statement (with instructions) was presented on screen to participants one at a time. Participants wrote their explanations in a text box that appeared below the statement. This constituted the explanatory reflection task. After advancing to the next screen, participants then re-rated the statement's profoundness. This process was repeated for each statement separately. The mean scores for these second profoundness ratings were labelled post-reflection ratings.

After completing the profoundness ratings and explanatory reflection task portions of the survey, participants then completed two measures of cognitive ability. Fluid intelligence was assessed using 10 items (five verbal reasoning, five matrix reasoning) from the International Cognitive Ability Resource (ICAR; Condon \& Revelle, 2014). Verbal crystallized intelligence was measured using a 10-item version of the "Wordsum" vocabulary test (Thorndike, 1942; Malhotra et al., 2007). Scores from each test were summed to provide separate measures of fluid and crystallized intelligence.

\section{Results}

Figure 1 shows mean profoundness scores by Statement Type (BS vs. non-BS) and Time (pre-reflection vs. post-reflection). We performed a $2 \times 2$ repeated-measures ANOVA with Statement Type (BS vs. non-BS) and Time (pre-reflection vs. post-reflection) which revealed a significant main effect of Statement Type, $F(1,158)=139.33, p<.001, \eta^{2}=.47$, demonstrating that mean profoundness scores for motivational non-BS statements were higher compared to those of pseudo-profound BS statements. There was also a significant main effect of Time, $F(1$, 
158) $=6.56, p=.011, \eta_{\mathrm{p}}^{2}=.04$, as well as a significant interaction between Statement Type and Time, $F(1,158)=36.08, p<.001, \eta_{\mathrm{p}}^{2}=.19$, indicating that profoundness ratings for pseudoprofound BS and motivational non-BS statements were affected differently by the reflection task. As illustrated in Figure 1, mean profoundness scores for BS statements before the reflection task $(M=2.86, S D=0.84)$ were significantly higher compared to after the reflection task $(M=2.59$, $S D=0.90), t(158)=6.05, p<.001, d=0.48,95 \% \mathrm{CI}[0.32,0.64]$. Alternatively, mean profoundness scores for non-BS statements before the reflection task $(M=3.59, S D=0.81)$ were significantly lower compared to those after the reflection task $(M=3.70, S D=0.84), t(158)=$ $2.44, p=.016, d=-0.19,95 \%$ CI $[-0.35,-0.04]$. In other words, reflection decreased the perceived profoundness of bullshit statements, but increased the perceived profoundness of motivational statements. Finally, we found no significant associations between changes in profoundness ratings for BS and non-BS statements and scores for fluid intelligence or crystallized verbal intelligence (intercorrelations between all variables can be found in the supplementary materials). 


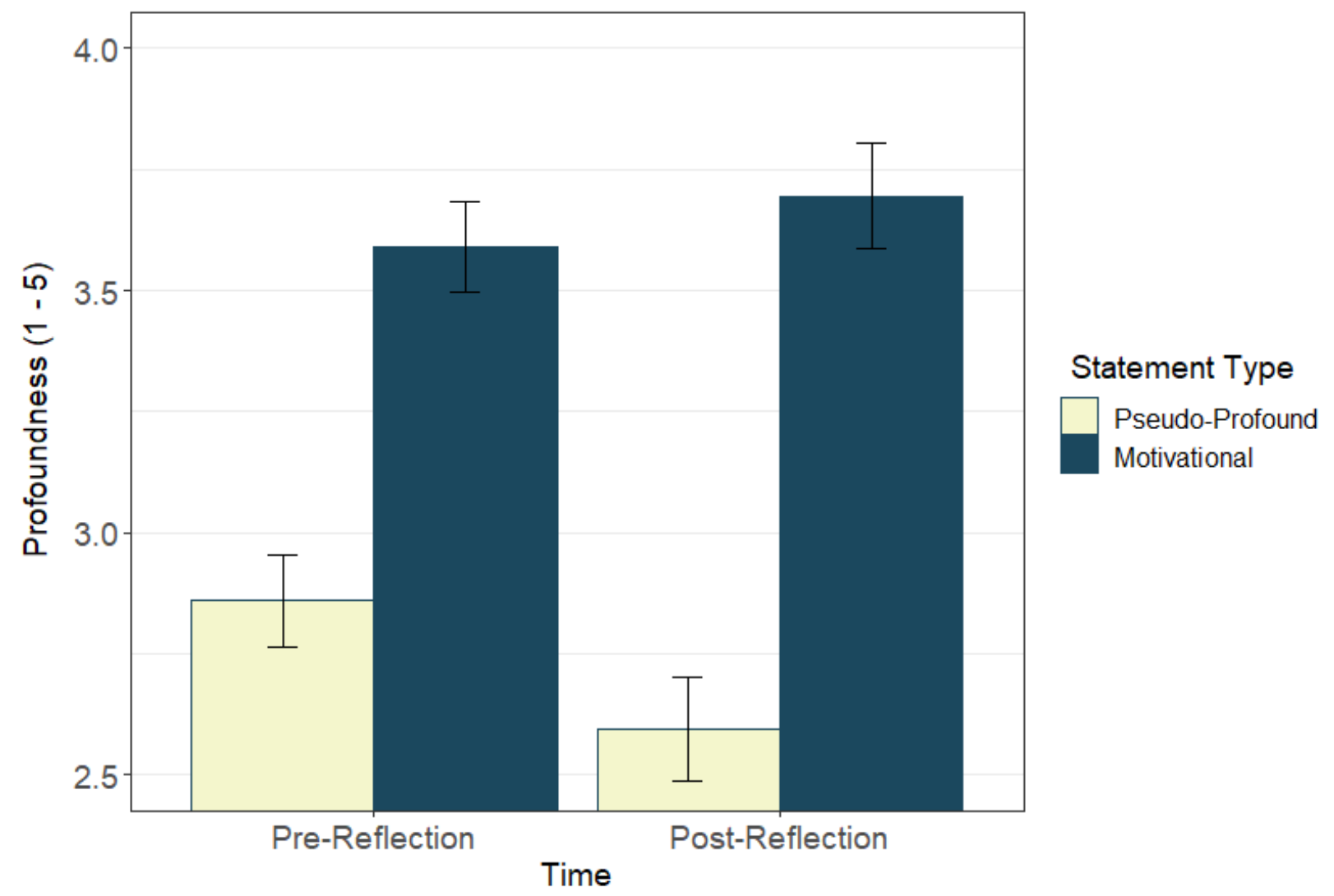

Figure 1. Mean differences in profoundness ratings for pseudo-profound (BS) and motivational (non-BS) statements relative to Time (before the reflection task and after the reflection task). Error bars represent $95 \%$ within-subject confidence intervals.

\section{Discussion}

Experiment 1 showed that attempting to explain in detail what makes an ambiguous statement (i.e., pseudo-profound bullshit) profound decreases the judged profoundness of the statement. However, attempting to explain what makes an intentionally motivational statement profound increases its judged profoundness, indicating that detail-focused reflection improved people's ability to distinguish meaningful from non-meaningful information. We also found that this pattern could not be explained by individual differences in fluid or crystallized intelligence. Taken together, these results provide initial evidence that susceptibility to pseudo-profound bullshit is supported by an illusion of understanding which can be attenuated by making people 
aware of the gaps in their understanding of what makes the statement profound.

\section{Experiment 2}

Experiment 2 is designed to accomplish two main goals. One is to replicate our results from Experiment 1 in a non-student sample. The other is to investigate to what extent purported “guru effects” might influence our results (Ilić \& Damnjanović, 2021; Sperber, 2010). The statements in Experiment 1 were presented with no source attributed to them (i.e., anonymous). However, much of the bullshit people encounter is online, particularly social media, where sources of bullshit information are more obvious (e.g., Tweets from public figures), or can at least be reasonably inferred (The Pearson Institute et al., 2021). Moreover, people often perceive bullshit statements from purported experts as more meaningful and convincing than bullshit attributed to anonymous sources, a phenomenon known as the "guru effect" (Gligorić \& Vilotijević, 2019; Ilić \& Damnjanović, 2021; Sperber, 2010). In other words, people find meaningless statements more meaningful when they come from a person who is highly respected or perceived to be an authority (e.g., guru, expert, etc.).

Guru effects may also inflate illusions of understanding, which can sometimes manifest as a person believing they understand or know more about a topic when told that experts fully understand the topic (Sloman \& Rabb, 2016). This may be the result of a person confusing their awareness that experts possess knowledge of some phenomenon, with a feeling that they, too, possess that knowledge (Rabb et al., 2019). For example, with regard to their perceived knowledge of economic issues, people start to discern expert from lay opinion only after having an illusion of explanatory depth exposed (Meyers et al., 2020). Given these findings, it is reasonable to hypothesize that an illusion of understanding task (i.e., having participants engage 
in detail-focused reflection through explanation) will not only reduce receptivity to bullshit statements, but might also help attenuate any purported guru effects for those statements.

\section{Method}

\section{Participants}

Data files and pre-registration information for Experiment 2 can be found here: https://osf.io/2tndf/. We recruited 150 participants from the United States and Canada from Amazon's Mechanical Turk participant pool using the crowdsourcing platform, CloudResearch (Litman et al., 2016). This sample size was based on our goal of achieving at least .80 power to detect a small-to-medium-sized effect at $\alpha=.05$ ( $\mathrm{g} *$ power; Faul et al., 2009) while allowing for possible exclusions which might result from our pre-registered exclusion criteria. We implemented several measures to ensure high data quality (e.g., Chmielewski et al., 2020; Ophir et al., 2020), the first of which was restricting recruitment to participants who had completed a minimum of 500 surveys and had an MTurk HIT approval rating of at least 99\%. Additionally, following procedures from Littrell and Fugelsang (2021), we utilized two pre-survey eligibility questions known as "botchas" which were designed to limit the number of fake responders gaining access to our survey (e.g., survey farmers using algorithmic "bots" to generate survey responses). Of the 150 who passed the eligibility criteria, data for 16 participants were removed for failing to pass reCAPTCHA v3 bot detection protocols or for failing an attention check, leaving 136 participants (71 male, 65 female, $\mathrm{M}_{\text {age }}=39.84, \mathrm{SD}_{\text {age }}=11.72$, Bachelor's degree or higher $=58.1 \%$ ). Participants were paid \$2.25 USD for the roughly 15 minute survey. 


\section{Procedure and Materials}

Informed consent and online survey presentation procedures were the same as those from Experiment 1. Participants were randomly assigned to two groups. The first group $(n=71)$ rated 5 BS statements (pseudo-profound) and 5 non-BS statements (motivational) presented in randomized order with no source attributed (i.e., anonymous). The second group $(n=65)$ rated the same 10 statements but, in this condition, each statement was attributed to an authoritative source. ${ }^{2}$ For example, whereas participants in the anonymous source condition would rate the statement, "Hidden meaning transforms unparalleled abstract beauty" with no source attributed to it, those in the expert source condition would rate the same statement attributed to a guru or other authoritative figure, "Hidden meaning transforms unparalleled abstract beauty Confucius, ancient Chinese philosopher." The names of sources were randomly assigned to each bullshit and non-bullshit statement using Microsoft Excel's RAND() function. As with Experiment 1, both groups rated all items twice: pre-reflection ratings were given first followed by the explanatory reflection task and post-reflection ratings.

\section{Results}

Mean profoundness scores for each Source (Anonymous vs. Expert) by Statement Type (BS vs. non-BS) and Time (pre-reflection vs. post-reflection) are displayed in Figure 2. We conducted a 2 Statement Type (BS vs. non-BS) by 2 Time (pre-reflection vs. post-reflection) by 2 Source (Anonymous vs. Expert) mixed-design ANOVA. Source of the statement was the between-subjects factor. We found no significant main effect of Source, $F(1,134)=2.89, p=$ $.09, \eta_{\mathrm{p}}^{2}=.02$, nor did we find a significant three way Statement Type $\mathrm{x}$ Time $\mathrm{x}$ Source

\footnotetext{
${ }^{2}$ A full list of statements with author names can be found in the supplementary materials.
} 
interaction, $F(1,134)<1$. However, results did indicate a significant main effect of Statement Type, $F(1,134)=58.13, p<.001, \eta^{2}=.30$, showing that mean profoundness scores for non-BS statements $(M=3.64, S D=0.76)$ were higher compared to those of BS statements $(M=2.89, S D$ $=1.04)$. We found no significant main effect of Time, $F(1,134)=2.79, p=.10, \eta^{2}{ }_{p}=.02$, but there was a significant, though small, interaction between Statement Type and Time, $F(1,134)=$ 4.52, $p=.04, \eta_{\mathrm{p}}^{2}=.03$, indicating that profoundness ratings for pseudo-profound $\mathrm{BS}$ and motivational non-BS statements were affected differently by the reflection task. Specifically, overall mean profoundness scores for BS statements before the reflection task $(M=2.95, S D=$ 0.98) were significantly higher compared to those after the reflection task $(M=2.84, S D=1.15)$, $t(135)=2.65, p=.009, d=0.23,95 \% \mathrm{CI}[0.06,0.40]$. However, initial mean profoundness scores for non-BS statements $(M=3.64, S D=0.73)$ did not significantly change after the reflection task $(M=3.64, S D=0.87), t(135)=.05, p=.959$. 


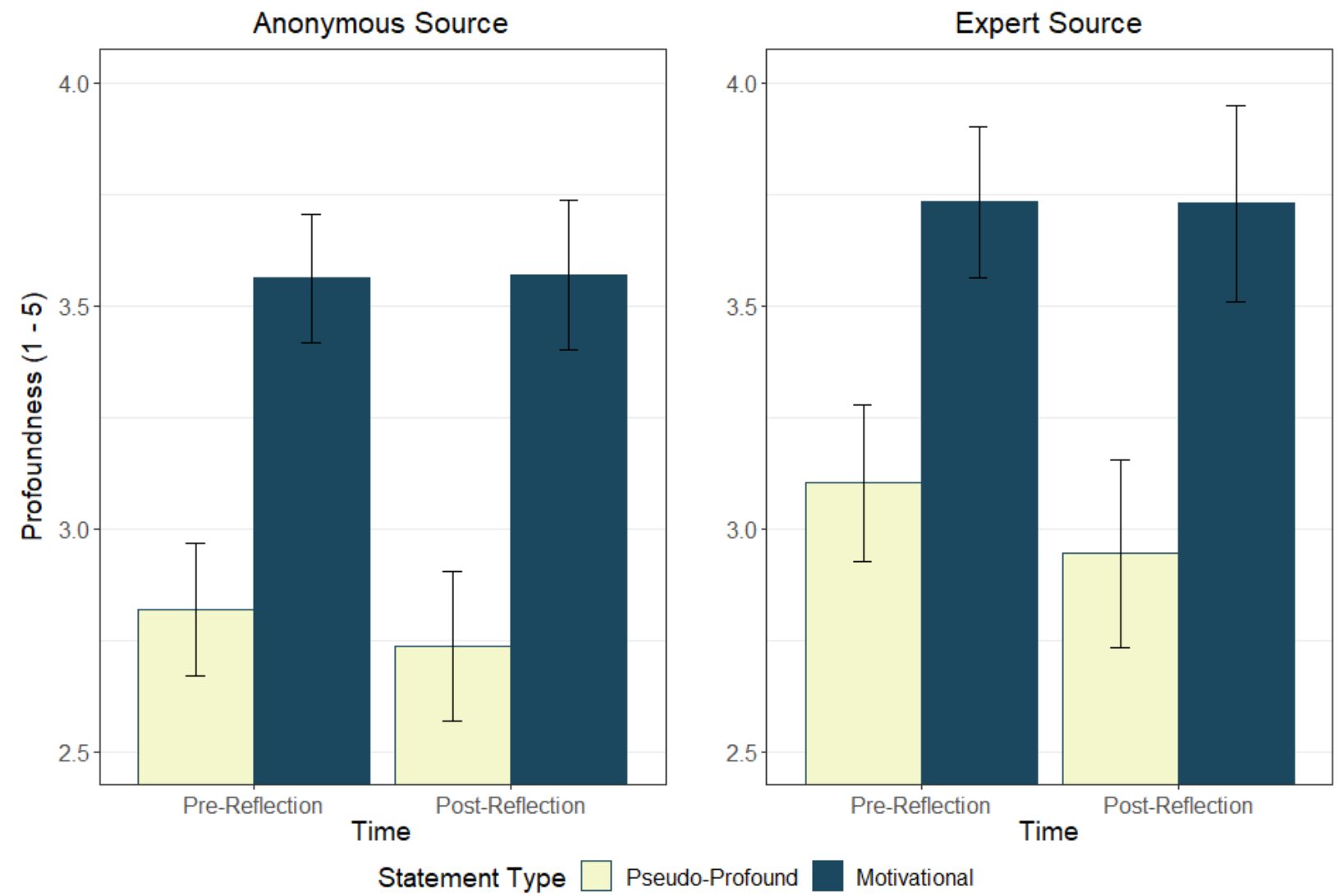

Figure 2. Mean differences in profoundness ratings by Source (Anonymous vs. Expert) for pseudo-profound (BS) and motivational (non-BS) statements relative to Time (before the reflection task and after the reflection task). Error bars represent $95 \%$ within-subject confidence intervals.

\section{Discussion}

In Experiment 2, we again found that trying to explain the meaning behind a pseudoprofound bullshit statement led to a reduction in the judged profoundness of that statement. In contrast, trying to explain a motivational statement did not affect the judged profoundness of that statement. This pattern suggests that susceptibility to pseudo-profound bullshit relies, at least in part, on people successfully fooling themselves into believing they understand the meaning behind a statement more than they really do. Fortunately, through reflecting on and attempting to explain what makes the statement profound, people can recognize the limits of their own understanding and adjust their profoundness judgments accordingly. In other words, detail- 
oriented reflection can help people "unbullshit" themselves.

We also found no effect of Source, which was surprising given that past studies have found that pseudo-profound bullshit is rated as more profound when attributed to credible or expert sources than when no source is given (Gligorić \& Vilotijević, 2019; Hoogeveen et al., 2020; Ilić \& Damnjanović, 2021). However, much of the bullshit that people are exposed to is encountered online (Simpson, 2019) and the way that we presented our stimuli is noticeably dissimilar to the visual formats more common to the ways in which misinformation is often presented online, particularly on social media (e.g., memes, fake news headlines, social media comments, etc.). As such, we suggest our lack of effect may stem from low ecological validity in our stimuli materials. For example, Gligorić and Vilotijević (2019) used stimuli which presented pseudo-profound bullshit within brief descriptive vignettes rather than as single statements. Hoogeveen and colleagues (2020) found a significant effect of source for pseudo-profound bullshit statements when presented in a visual format more similar to online memes that people often encounter while on social media. Likewise, Ilić and Damnjanović (2021) presented bullshit statements in a similar way to how purportedly inspirational quotes are often shared online, with detailed references (randomly assigned to each statement) which included an author name followed by a year, a location where the statement was purportedly made, and a source (e.g., book, interview, or letter) for each statement. As our stimuli were presented as black letters against a white screen, it is reasonable to assume that our presentation format was too dissimilar to the ways in which bullshit statements are often encountered in everyday life, as well as in previous work, to be sufficiently engaging to participants. Therefore, in Experiment 3, we attempted to remedy this limitation by utilizing more ecologically valid stimuli. 


\section{Experiment 3}

Experiments 1 and 2 established that engaging in detail-oriented reflection can expose an illusion of understanding and, consequently, decrease receptivity to pseudo-profound bullshit. Reduced bullshit receptivity was demonstrated by a decrease in profoundness ratings over time for pseudo-profound bullshit but not for motivational statements. In Experiment 2, we failed to find an effect for Source of the statements and we hypothesized that this was due to our stimuli having low ecological validity. In Experiment 3, we remedy this by using stimuli that are more visually representative of how bullshit statements are often shared online. Additionally, people are often influenced by misinformation that falls outside the realm of the pseudo-profound. For example, many people find superfluous scientific language to be appealing and persuasive (Fernandez-Duque et al., 2015), a phenomenon that some companies take advantage of by using scientific language when marketing consumer products (Fowler et al., 2019).

While scientific language can be helpful for clarifying important, complex topics, it can also be used to mislead the public, possibly into believing that they understand a topic more than they really do (Evans et al., 2020; Goldacre, 2010; Rhodes et al., 2014). Therefore, in Experiment 3, we expand the scope of our investigation to test the generalizability of our findings by including stimuli which represent scientific bullshit. This is important because illusion of understanding effects have failed to materialize for some knowledge domains, particularly those that draw more heavily from rote memory processes (Rozenblit \& Keil, 2002). For example, an illusion of understanding has been found when asking people to explain how complex mechanical devices operate (e.g., sewing machines), describe natural phenomena (e.g., how snow forms), and elaborate on political concepts (e.g., how trade with China affects the US economy) (Johnson et al., 2016; Meyers et al., 2020; Vitriol \& Marsh, 2018). However, the 
illusion has not been found for knowledge based on the recall of objective facts (e.g., capital cities of the world) or steps in basic behavioural procedures (e.g., how to bake chocolate chip cookies; Rozenblit \& Keil, 2002). As such, if scientific bullshit statements are construed as representing a fundamentally different type of knowledge domain than pseudo-profound bullshit, then deliberation could reduce receptivity to one type of bullshit but not the other. However, it is also possible that pseudo-profound and scientific bullshit are construed and evaluated in similar ways (i.e., "it's all bullshit"), thus an illusion of understanding reflection task would reduce receptivity for both.

\section{Participants}

We recruited two samples of 150 participants each for Experiment $3{ }^{3}$ One sample rated only pseudo-profound bullshit and intentionally profound statements while the other rated scientific bullshit and real scientific statements (data files and materials available here:

https://osf.io/2tndf/). Recruitment and sample size procedures were identical to Experiment 2 (i.e. minimum of 500 surveys completed, minimum 99\% MTurk HIT approval rating, passing two pre-survey botchas). Of the 150 in each sample who passed the eligibility criteria, data for 19 participants were removed (Pseudo-profound BS sample $=7$; Scientific BS sample $=12$ ) for failing to pass reCAPTCHA v3 bot detection protocols or for failing an attention check, leaving 143 participants in the pseudo-profound bullshit condition (64 male, 78 female, 1 prefer not to answer, $\mathrm{M}_{\text {age }}=44.06, \mathrm{SD}_{\text {age }}=14.46$, Bachelor's degree or higher $\left.=57.3 \%\right)$ and 138 participants in the scientific bullshit condition (75 male, 63 female, $\mathrm{M}_{\text {age }}=44.70, \mathrm{SD}_{\text {age }}=14.99$, Bachelor's

\footnotetext{
${ }^{3}$ Due to reportedly insufficient blood plasma levels of caffeine in the lead author, Experiment 3 was not preregistered before data collection began. Therefore, data collection and analyses were conducted in accordance with pre-registered protocols from Experiment 2.
} 
degree or higher $=65.9 \%$ ) for our analyses. Participants were paid $\$ 2.25$ USD for the roughly 15-minute survey.

\section{Procedure and Materials}

Recruitment and survey administration procedures were the same as those of the previous two studies. Participants in each sample (Pseudo-profound bullshit, Scientific bullshit) were randomly assigned to one of two Source conditions. The Anonymous Source (Pseudo-profound BS sample, $n=67$; Scientific BS sample, $n=61$ ) rated 5 bullshit statements and 5 real statements presented in randomized order with no source attributed (i.e., anonymous). The Expert Source condition (Pseudo-profound BS sample, $n=76$; Scientific BS sample, $n=77$ ) rated the same 10 statements attributed to an authoritative source. Participants in the pseudoprofound sample rated the "profoundness" of the statements while those in the scientific sample rated the "truthfulness" of the statements. Additionally, in Experiment 3 we changed our response scale range from a 5-point scale to a 7-point scale ("Not at all profound/truthful" to "Extremely profound/truthful") to conform with the standard rating range used in previous illusion of explanatory depth studies (e.g., Fernbach et al., 2013; Johnson et al., 2016). All participants rated items before and after the reflection task. Names of sources were again randomly assigned to each bullshit and non-bullshit statement using Microsoft Excel's RAND() function.

Based on procedures from Hoogeveen and colleagues (2020), stimuli were redesigned to mimic a visual format more similar to how inspirational quotes and bullshit statements are often encountered online. Both bullshit and non-bullshit statements were presented to participants in random order in an "internet meme" picture format with a rating scale positioned below the 
picture. The picture was presented on-screen again during the reflection task as well as during the post-reflection rating. As illustrated in Figure 3A, for the 10 statements rated in the pseudoprofound BS sample, statements attributed to expert sources included the names of historically significant intellectual and social figures (e.g., Confucius, Martin Luther King, Jr.). A picture of the expert appeared on the left-hand side of the screen with the statement (in quotes) in a box on the right with the name of the source appearing after the statement. As illustrated in Figure 3B, for the 10 statements rated in the scientific BS sample, names of experts were all well-known scientists (e.g., Albert Einstein, Neil DeGrasse Tyson). Participants in the groups who rated anonymous statements were shown only the statement with no source attributed to it presented in a similar format to that of the expert group stimuli. The full set of stimuli can be found in the supplementary materials.
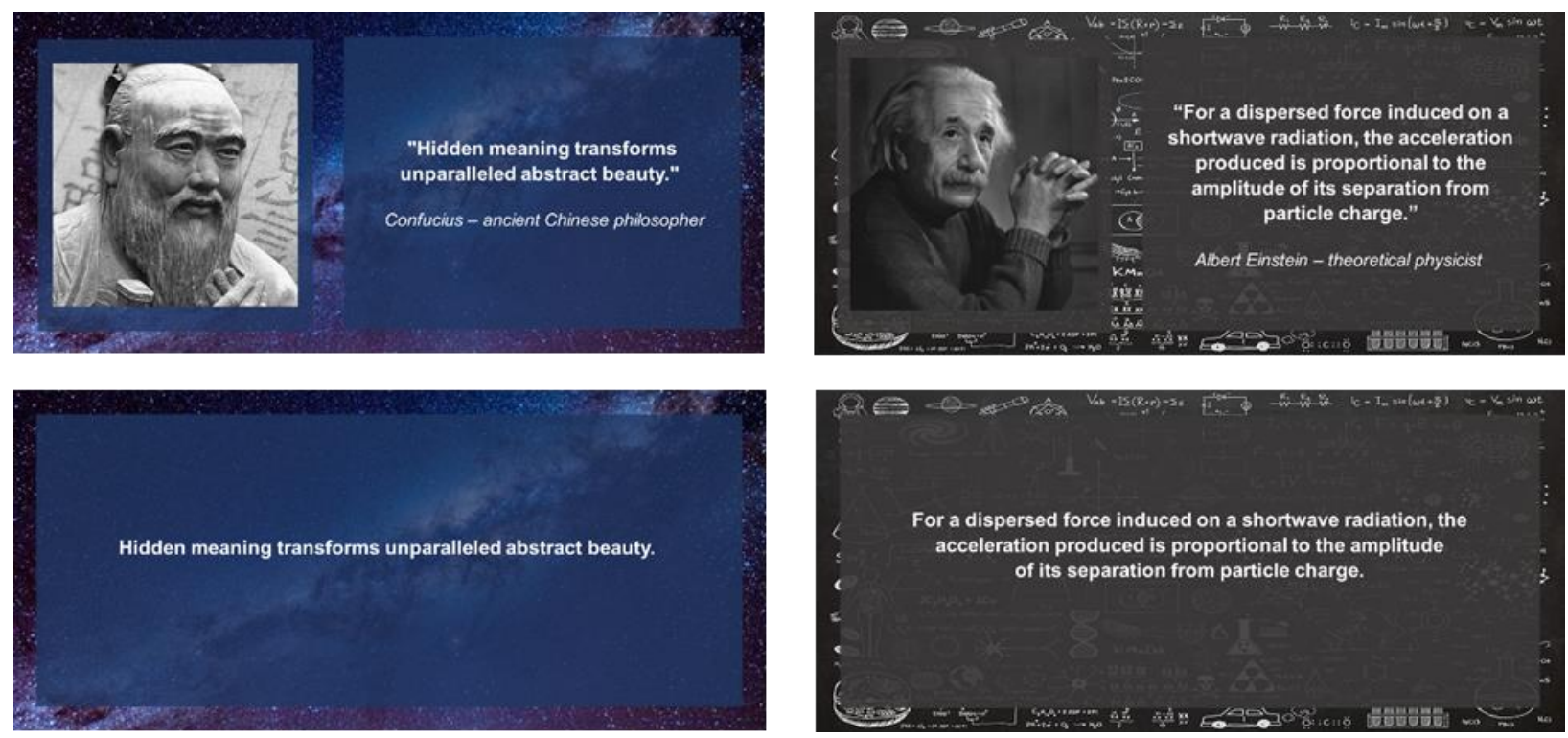

(A) Pseudo-profound BS

(B) Scientific BS

Figure 3. Example stimuli used in Experiment 3. Column A represents stimuli rated by participants in the Pseudo-profound BS sample for those in the Expert Source condition (top) and those in the Anonymous Source condition (bottom). Column B represents stimuli rated by participants in the Scientific BS sample for those in the Expert Source condition (top) and the Anonymous Source condition (bottom). 


\section{Results}

We analyzed results for the Pseudo-profound BS and Scientific BS samples separately. For each sample, we conducted a 2 Statement Type (BS vs. Non-BS) by 2 Time (pre-reflection vs. post-reflection) by 2 Source (Anonymous vs. Expert) mixed-design ANOVA. Source of the statement was the between-subjects factor in both samples.

\section{Pseudo-profound bullshit}

Mean profoundness scores for each Source (Anonymous vs. Expert) by Statement Type (BS vs. non-BS) and Time (pre-reflection vs. post-reflection) are displayed in Figure 4A and 4B. Consistent with Experiments 1 and 2, we found a significant main effect of Statement Type, $F(1$, $141)=55.90, p<.001, \eta^{2}=.28$, indicating that overall mean profoundness ratings for non-BS (motivational quotes) were higher than ratings for pseudo-profound BS. We also found a significant main effect of Time, $F(1,141)=6.92, p=.009, \eta^{2}{ }_{p}=.05$, which was qualified by a significant Statement Type $\mathrm{x}$ Time interaction, $F(1,141)=8.37, p=.004, \eta^{2}=.06$, indicating that ratings for pseudo-profound and motivational statements were affected differently by the reflection task. Specifically, mean profoundness scores for BS statements were significantly higher before the reflection task $(M=4.46, S D=1.31)$ compared to after $(M=4.21, S D=1.55)$, $t(142)=3.92, p<.001, d=.33,95 \%$ CI $[0.16,0.50]$. Additionally, replicating Experiment 2, mean profoundness scores for motivational statements were not significantly different before reflection $(M=5.25, S D=1.23)$ compared to after $(M=5.26, S D=0.98), t(142)=.26, p=.797$. We also found a significant main effect of Source, $F(1,141)=9.58, p=.002, \eta^{2}{ }_{p}=.06$, indicating that mean profoundness ratings for BS and non-BS statements were higher in the Expert Source condition compared to the Anonymous Source condition. Finally, we found no 
significant interactions of Statement Type x Source, Time x Source, or Statement Type x Time x Source, all $F \mathrm{~s}<1$.
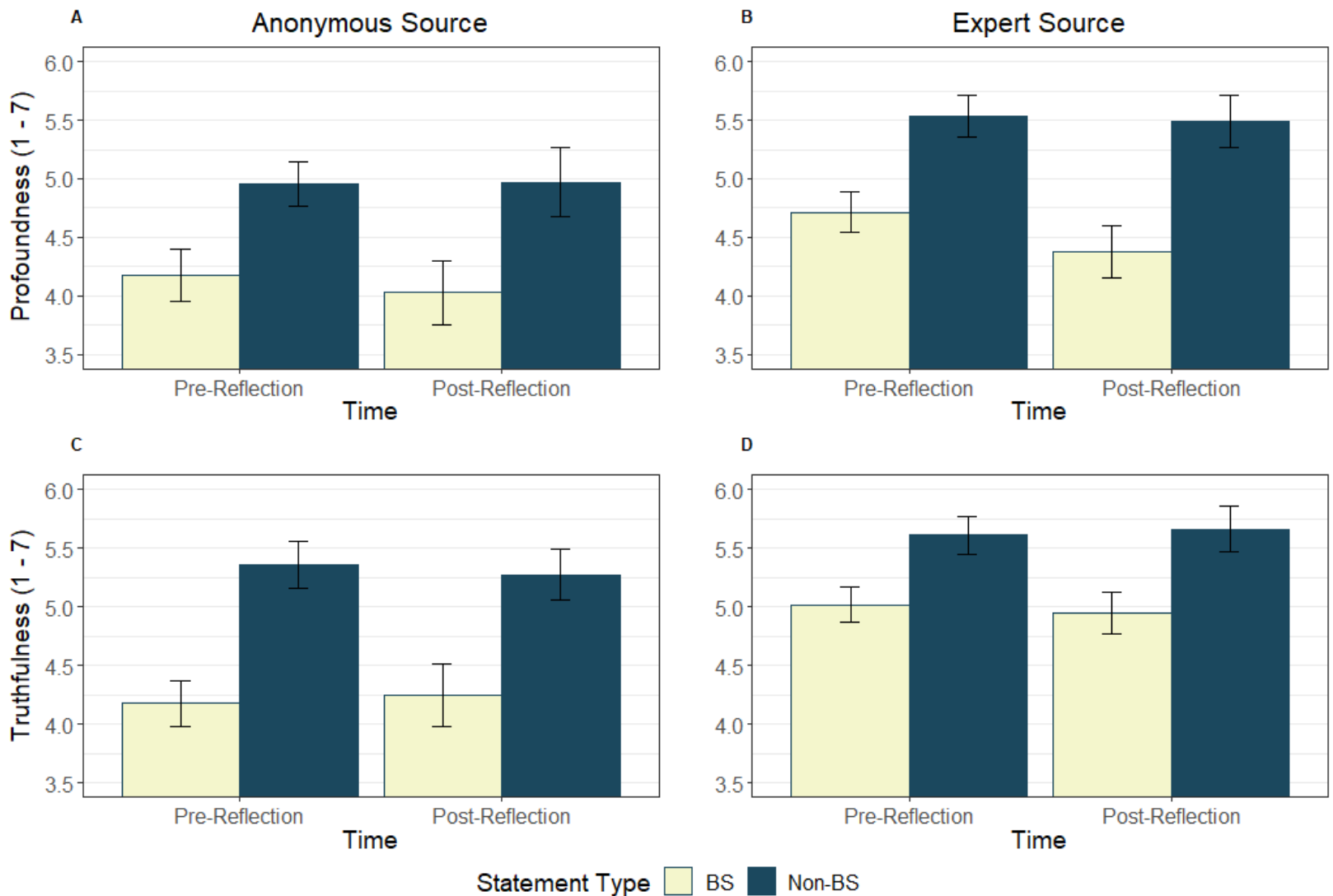

Figure 4. Mean differences in profoundness (A, B) and truthfulness (C, D) ratings by Source (Anonymous vs. Expert) for BS and non-BS statements relative to Time (before the reflection task and after the reflection task). Error bars represent $95 \%$ withinsubjects confidence intervals.

\section{Scientific bullshit}

Mean truthfulness scores for each Source (Anonymous vs. Expert) by Statement Type (BS vs. non-BS) and Time (Pre-reflection vs. Post-reflection) are displayed in Figure 4C and 4D. We found a significant main effect of Statement Type, $F(1,135)=93.10, p<.001, \eta^{2}=.41$, indicating that mean truthfulness ratings for real scientific statements were significantly higher than ratings for scientific bullshit statements. However, we found no significant main effect of 
Time, nor any significant interactions of any variables with Time, all $F_{\mathrm{S}}<1$. This suggests that engaging in detail-focused reflection did not affect perceived truthfulness of scientific bullshit statements or real scientific statements. Additionally, we found a significant effect of Source, $F(1,135)=11.90, p<.001, \eta_{\mathrm{p}}^{2}=.08$, indicating that overall mean truthfulness ratings for scientific bullshit and real scientific statements were higher when attributed to expert sources than when statements were anonymous. This was qualified by a significant Statement Type $\mathrm{x}$ Source interaction, $F(1,135)=5.90, p=.016, \eta_{\mathrm{p}}^{2}=.04$, in which mean ratings for scientific bullshit from experts were significantly higher than those from anonymous sources both before (Expert: $M=5.02, S D=1.27$; Anonymous: $M=4.18, S D=0.96), t(136)=0.26, p<.001$, and after (Expert: $M=4.94, S D=1.42$; Anonymous: $M=4.25, S D=1.25), t(135)=-3.07, p=.003$, the reflection task. However, scores for real scientific statements from experts and anonymous sources were not significantly different before reflection (Expert: $M=5.61, S D=0.94$; Anonymous: $M=5.35, S D=0.93 ; t(129)=1.59, p=.115)$ and only marginally significantly different after reflection (Expert: $M=5.66, S D=1.20$; Anonymous: $M=5.27, S D=1.04 ; t(134)$ $=2.03, p=.045)$.

\section{Discussion}

In Experiment 3, we again found evidence that people perceive pseudo-profound bullshit statements as less profound after attempting to provide detailed explanations of those statements. However, this effect did not extend to scientific bullshit. Indeed, trying to explain the meaning of scientific bullshit did not significantly affect its perceived truthfulness. Crucially, these findings represent a potential boundary condition for the effectiveness of attempting to puncture an illusion of understanding to reduce one's receptivity to certain types of bullshit. Specifically, engaging in detail-oriented reflection appears to be insufficient to expose an illusion of 
understanding for scientifically nonsensical statements. Furthermore, this suggests that some types of bullshit (e.g., pseudo-profound, scientific) may be qualitatively different in terms of how they are construed and evaluated by people. Therefore, it may be necessary to develop interventions that can be adjusted to combat the persuasiveness of different types of misleading information.

We also found evidence for "guru effects" for both pseudo-profound and scientific bullshit. That is, bullshit is judged to be more profound or truthful when it comes from a perceived expert or authoritative source than when presented by itself. This effect also applied to non-bullshit information (i.e., motivational quotes and real scientific statements). Furthermore, scientific bullshit coming from expert sources was rated as significantly more truthful than scientific bullshit from anonymous sources both before and after reflecting on it. Additionally, the "guru effect" did not prohibit or weaken the tempering effect that explaining bullshit had on believing bullshit. Taken together, these findings suggest the presence of at least two distinct mechanisms responsible for an individual's receptiveness to bullshit (i.e., illusion of understanding and guru/expert effects) that do not appear to apply equally to all types of bullshit. Given these results showing that different types of misleading information may be processed and evaluated in different ways, in Experiment 4 we sought to investigate whether these effects exist for another common type of misleading information arguably similar to bullshit in many ways: fake news (e.g., Pennycook \& Rand, 2020).

\section{Experiments $4 \mathrm{a}$ and $\mathbf{4 b}$}

In Experiment 4, we expand our investigation by examining an illusion of understanding for fake news, defined as "fabricated information that mimics news media content in form but not in organizational process or intent” (p. 1094, Lazer et al., 2018). As Pennycook and Rand 
(2020) have noted, fake news is often constructed with the goal of "going viral" rather than conveying truthfulness or accuracy. A lack of concern for communicating truthful or accurate content is also a key feature of bullshit (Littrell \& Fugelsang, 2021; Pennycook et al., 2015) and recent work has found positive associations between receptivity to fake news and bullshit receptivity (Littrell et al., 2021; Pennycook \& Rand, 2020). Additionally, fake news receptivity and pseudo-profound bullshit receptivity share correlations with various measures of analytic thinking and epistemically-suspect beliefs (Pennycook et al., 2015; Pennycook \& Rand, 2020), pointing to the possibility that a reflection-based intervention might curtail the influence of fake news as it does for pseudo-profound BS. However, given our findings for scientific bullshit, it is also possible that people might construe news headlines (whether fake or real) as falling into a knowledge domain for which an illusion of understanding would not apply (e.g., facts). If this is the case, then engaging in detail-oriented reflection may not affect receptivity to fake news. Therefore, in Experiments $4 \mathrm{a}$ and $4 \mathrm{~b}$, we consider both possibilities as we investigate whether an illusion of understanding underlies receptivity to fake news headlines.

\section{Participants}

Experiments $4 \mathrm{a}$ and $4 \mathrm{~b}$ were conceptually identical ( $4 \mathrm{~b}$ was intended as a replication of 4a), thus will be reported together here. A sample of 150 participants was recruited for Experiment $4 \mathrm{a}$ and 125 participants for Experiment $4 \mathrm{~b} .{ }^{4}$ Recruitment procedures were identical to Experiments 2 and 3 with an additional criterion that total response times below 300 seconds would be excluded from analysis, as such a completion time for a roughly 3000-word survey would represent reading speeds dramatically faster than those of an average human (i.e., 250-300

\footnotetext{
${ }^{4}$ Results from Experiments 3 and 4a showed that we were overestimating our anticipated exclusions, so we reduced the number of participants we recruited in Experiment $4 \mathrm{~b}$.
} 
wpm). Of the participants in each sample who passed the eligibility criteria, data were removed for 20 participants in Experiment $4 \mathrm{a}$ and 13 participants in $4 \mathrm{~b}$ according to our pre-registered exclusion criteria. This left data for 130 participants in Study $4 \mathrm{a}$ (74 male, 56 female, $\mathbf{M}_{\text {age }}=$ 39.65, $\mathrm{SD}_{\text {age }}=12.26$, Bachelor's degree or higher $\left.=59.2 \%\right)$ and 112 participants for Study $4 \mathrm{~b}$ (67 male, 45 female, $\mathrm{M}_{\text {age }}=39.88, \mathrm{SD}_{\text {age }}=11.30$, Bachelor's degree or higher $=51.8 \%$ ). Participants were paid \$2.25 USD for the roughly 15-minute surveys.

\section{Procedure and Materials}

Data files, materials, and pre-registration for Experiment $4 \mathrm{a}$ and $4 \mathrm{~b}$ can be found here: https://osf.io/2tndf/. All participants in Experiment 4a rated the accuracy of 5 politically-neutral fake headlines and 5 politically-neutral real headlines twice - before and after the reflection task - on a scale from 1 ("Not at all accurate") to 7 ("Extremely accurate"). Each participant was randomly assigned to one of two groups. The first group $(n=65)$ rated headlines that were attributed to well-known, mainstream news organizations (e.g., New York Times, The Washington Post). The second group $(n=65)$ rated the same headlines but attributed to sources that have been identified by Snopes.com and Politifact.com as known purveyors of fake news content (e.g., Now8News, BreakingNews13). All headlines were presented in random order and in the same format as they would appear in a Facebook post; a story-relevant picture accompanied by a lede-type title and the website source printed below. The fake news headlines were taken from lists of popular fake news items debunked by authoritative, fact-checking sources (e.g., Snopes.com, Politifact.com), while the real news headlines were taken from the websites of mainstream news organizations (e.g., New York Times, The Washington Post, etc.). Names of news sources (credible and non-credible) were randomly assigned to each headline using Microsoft Excel's RAND() function. To ensure that source information was clear to 
participants, the source's logo was superimposed on the bottom right-hand corner of each picture. All stimuli and instructions can be found in the supplementary materials.

\section{Results}

\section{Experiment $4 a$}

Mean accuracy ratings for each Headline Type by Time and Source are illustrated in panels $\mathrm{A}$ and $\mathrm{B}$ of Figure 5. We found a significant main effect of Headline Type, $F(1,128)=$ 381.32, $p<.001, \eta^{2}=.75$, indicating that participants rated real news headlines as more accurate than fake news headlines. This is consistent with our previous findings for profoundness ratings of bullshit statements compared to non-bullshit statements. We also found a marginally significant main effect of Source, $F(1,128)=3.83, p=.053, \eta^{2} \mathrm{p}=.03$, indicating that headlines attributed to a credible source were judged as somewhat more accurate than those attributed to a non-credible source. Finally, we found no significant effect for Time or any interaction effects (all $F \mathrm{~s}<1)$. 

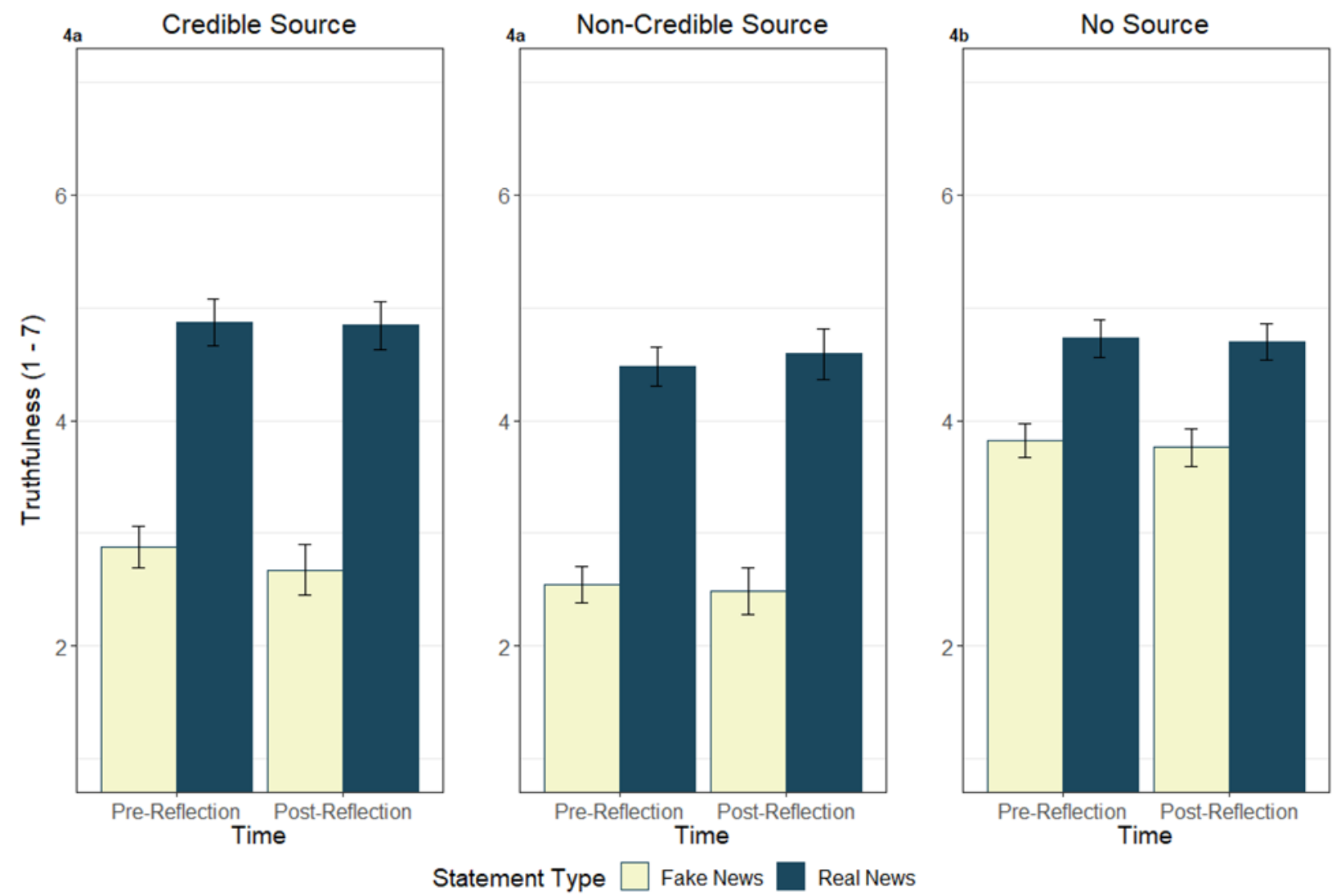

Statement Type $\square$ Fake News $\square$ Real News

Figure 5. Mean differences in accuracy ratings by Source (Experiment 4a: Credible vs. Non-Credible; Experiment 4b: No Source) for fake news headlines and real news headlines relative to Time (before the reflection task and after the reflection task). Error bands/bars represent $95 \%$ within-subjects confidence intervals.

\section{Experiment $4 b$}

The distribution of ratings for some of our headline stimuli in 4a were significantly positively skewed, so we hypothesized that our lack of a significant effect for Time may have been due to possible floor effects. Therefore, in Experiment 4b, we replicated our procedures from $4 \mathrm{a}$, restricting the stimuli to 3 fake headlines and 3 real headlines whose distributions were more normal. As the effect of Source in the previous trial was small and only marginally significant, and past research has also failed to find a consistent effect of source credibility for fake news (e.g., Pennycook \& Rand, 2019; but also see, Nadarevic et al., 2020), we removed the 
Source condition in Experiment 4b because we were not confident that it represented a replicable effect.

Panel $\mathrm{C}$ of Figure 5 illustrates mean accuracy ratings for fake news and real news headlines from Experiment 4b. As with Experiment 4a, we found a significant main effect of Headline Type, $\mathrm{F}(1,111)=51.68, \mathrm{p}<.001, \eta^{2} \mathrm{p}=.32$, and again found no significant effect for Time, nor did we find any significant interactions, all Fs $<1$. This indicates that our results from Experiment $4 \mathrm{a}$ were not due to floor effects and instead suggests that a detail-oriented reflection task is insufficient to reduce receptivity to fake news headlines.

\section{Discussion}

Experiment 4 expanded the scope of our investigation to test the efficacy of a detailfocused reflection task for reducing receptivity to fake news headlines. However, despite the correlational and conceptual similarities between fake news and pseudo-profound bullshit, attempting to give detailed explanations for the accuracy of fake news headlines did not significantly change people's ratings of those headlines. This suggests that, unlike receptivity to pseudo-profound bullshit (but similar to that of scientific bullshit), fake news receptivity does not appear to be supported by an illusion of understanding. Indeed, these results could represent another boundary condition for the effectiveness of using reflection alone as an intervention for reducing susceptibility to misinformation. Our results also confirm past research that has failed to find source credibility effects for perceptions of fake news (e.g., Pennycook \& Rand, 2020; Tsang, 2020), suggesting that other factors likely make more meaningful contributions to the extent to which a person finds fake headlines persuasive.

Additionally, Experiment 4 is similar to recent work by Bago and colleagues (2020) in 
which they compared accuracy ratings for politically neutral headlines ${ }^{5}$ in a two-response condition (initial, time-limited response vs. second response with no time limit) to a oneresponse (no time limit) condition, finding that deliberation reduced receptivity to fake news headlines in the two-response condition. For the two-response group, fake news headlines were given the highest accuracy ratings when participants responded under cognitive load with a 7second time limit (initial response). When participants rated the items a second time and under no time limit, ratings were significantly lower. However, it should be noted that accuracy ratings for fake news headlines were lowest in the one-response group (i.e., no time limit or cognitive load) compared to the two-response group. Likewise, accuracy ratings for real news headlines were highest in the one-response group compared to both responses in the two-response group.

This makes sense in light of Experiment 4's results because we gave participants as long as they would like to rate the news headlines both before and after the reflection task. This allowed participants to respond based on whatever thinking process was most natural for them (i.e., intuition or reflection). Though the findings from Bago and colleagues (2020) are noteworthy as a matter of theoretical interest (i.e., that accuracy ratings are higher for fake news and lower for real news when made under time pressure and cognitive load than when made with no time pressure or cognitive load), their generalizability to real-world behaviour is likely limited, as it would be unlikely that people evaluate news headlines under such and attention and time constrained manner. Consequently, our results suggest that when people are under no initial time pressure to evaluate misleading information, further deliberation appears to have little benefit in reducing receptivity to fake news headlines.

\footnotetext{
${ }^{5}$ Bago and colleagues (2020) also used politically biased headlines in a separate phase of the study. Though the results were similar, we focus here only on the findings for politically neutral headlines, as our headline stimuli were also politically neutral.
} 


\section{General Discussion}

Across four studies $(N=818)$, we demonstrated that an illusion of understanding underlies receptivity to some types of misinformation but not others. Experiments 1 and 2 showed that asking people to reflect on and describe in detail why they find certain statements meaningful (or not) helps reduce receptivity to pseudo-profound bullshit statements. Experiment 3 replicated these findings and expanded on them, showing that engaging in detail-oriented reflection significantly reduces receptivity to pseudo-profound bullshit but does not meaningfully affect receptivity to scientific bullshit. Furthermore, Experiment 4 found that receptivity to fake news headlines is not supported by an illusion of understanding and engaging in reflection did not reduce perceptions of fake news accuracy. Thus, we found evidence that the degree to which reflective thinking is an effective antidote to misinformation depends on the type of misinformation to which one has been exposed.

Additionally, we extend previous work demonstrating the enhancing effects of source credibility on receptivity to misinformation (Gligorić \& Vilotijević, 2019; Ilić \& Damnjanović, 2021). Specifically, while we found strong evidence in Experiment 3 that source credibility positively influences perceptions of pseudo-profound and scientific bullshit (i.e., "guru effects"), these effects did not extend to peoples' evaluations of the accuracy of fake news headlines in Experiment 4 . We also found that the source credibility effect was robust to puncturing an illusion of understanding. This is consistent with work demonstrating that failing to generate an explanation for how something works leads individuals to doubting the knowledge they themselves possess, but not the knowledge that others such as experts may possess (Meyers et al., 2020; Rabb et al., 2019; Rozenblit \& Keil, 2002). In the following, we expand on and provide broader context for these findings. 


\section{Not all bullshit is alike}

Researchers have identified several categories of bullshit, including pseudo-profound (Pennycook et al., 2015), scientific (Evans et al., 2020), political (Petrocelli, 2021), organizational (Spicer, 2020), and fake news (Pennycook \& Rand, 2020). These types of misinformation reflect a carefree indifference for conveying truth, accuracy, clarity, or meaning and are often used to impress, persuade, or otherwise mislead others (Littrell \& Fugelsang, 2021). Furthermore, receptivity to various types of bullshit is associated with a lack of analytic prowess, insufficient engagement in cognitive reflection, and overconfidence in one's bullshit detection abilities (Littrell \& Fugelsang, 2021; Littrell et al., 2021; Lyons et al., 2021; Pennycook \& Rand, 2020).

However, the results presented here reveal important differences in the extent to which reflective thinking can alter perceptions of various types of misinformation. Crucially, we found that engaging in detail-oriented, explanatory reflection leads to a reduction in receptivity to pseudo-profound bullshit but not to scientific bullshit or fake news. One possible explanation for these disparities is that different types of misinformation are construed as appealing to different domains of knowledge. For example, past work from Rozenblit and Keil (2002) suggests that the illusion of understanding does not extend to factual information (e.g., the capital of Utah), but does extend to knowledge that would require more elaboration to articulate (e.g., how a helicopter achieves lift). Scientific phenomena and news reports are generally viewed as being factual in nature. Therefore, people may evaluate scientific bullshit statements and fake news (e.g., "Energy can deteriorate based on closed-circuit alliterations of an afocal system") in the same way that they evaluate concrete facts (i.e., it is either accurate/truthful or it is not), thus limiting any effect reflective explanation might have in puncturing an illusion of understanding 
and reducing receptivity to that information. In contrast, the more metaphysical, New Age language used in pseudo-profound statements (e.g., "Consciousness is the growth of coherence, and of us") may be construed as involving spiritual or emotional phenomena that are more open to abstraction and subjective interpretation. As such, reflectively elaborating on a pseudoprofound statement would elucidate the details (or lack thereof) that were glossed over in one's initial judgment, resulting in the stimuli appearing less profound. As such, the extent to which bullshit receptivity is supported by an illusion of understanding appears to depend, at least partially, on which type of information a person construes bullshit statements to be (e.g., objective facts, abstract ideas, etc.) and whether those perceptions align with one of the knowledge domains for which the illusion effect has been demonstrated previously.

\section{Source credibility and illusion of understanding}

Experiment 3 demonstrated clear evidence of a "guru effect" for both pseudo-profound and scientific bullshit. That is, when paired with a reputable source, people perceived pseudoprofound bullshit as more profound and scientific bullshit as more truthful. Moreover, the same pattern was observed for motivational quotes and real scientific facts. The indiscriminate nature in which the guru effect manifests (i.e., equally for both meaningful and meaningless statements) is highly consistent with recent work demonstrating that people believe they understand a phenomenon more when told that it is fully understood by experts as compared to when told that it is not fully understood by experts (Sloman \& Rabb, 2016). Indeed, we suggest our findings represent a conceptual replication of this work as both profundity and truthfulness may represent perceived understanding. Furthermore, as the observed "guru effects" were robust to puncturing an illusion of understanding, our results conceptually replicate recent work demonstrating that people will revise their beliefs more to experts after having an illusion of understanding 
punctured compared to not having it punctured (Meyers et al., 2020). This suggests that failing to generate an explanation for how something works makes individuals doubt the knowledge they possess, but not the knowledge others possess. It is also consistent with the idea that recognizing we know less than we thought we did may indicate a recognition that we have mistaken knowing where we can access knowledge with actually possessing the knowledge ourselves (Rabb et al., 2019).

We believe these parallels have two important implications. The first is that our work provides additional evidence for the community of knowledge hypothesis that people fail to distinguish their own knowledge from the knowledge of others (Sloman \& Fernbach, 2017; Welbourne, 1981). Our results demonstrate that associating an idea or scientific claim with an apparent authoritative individual increases the perceived validity of that information, even when it cannot possibly be true. In this way, our results demonstrate both an undeniable benefit and a pernicious consequence of a community of knowledge. Truthful information about the world can spread rapidly, as can bullshit, falsehoods and lies. The second implication is that our work suggests that the guru effect may be enabled by the community of knowledge. Under this view, gurus can represent individuals who are perceived to possess specialized knowledge and the store of the evidence for that knowledge. Thus, "scientific gurus" are individuals capable of moving lay opinion on scientific issues regardless of whether what they are saying is factually correct or not as people in part rely on them to know these things. This is further supported by recent work demonstrating that only after having an illusion of understanding punctured will people revise their opinions on economic issues more to professional economists (one type of "guru") than to laypeople (Meyers et al., 2020). In other words, only when "gurus" are perceived 
to have privileged information above and beyond what laypeople (or a given individual) may possess are they able to shift the minds of others.

\section{The limits of reflective thinking as a strategy against misinformation}

At first glance, the results reported here may appear to somewhat conflict with "miserly processing" accounts which assert that falling for bullshit and fake news stems from a tendency to rely on quicker, lower-effort intuitive thinking processes while avoiding engagement in more deliberative, effortful reflection when evaluating information (Bago et al., 2020; Pennycook \& Rand, 2019, 2020). These claims draw support from studies correlating receptivity to various types of misleading information with performance on the Cognitive Reflection Test (CRT; Frederick, 2015), a cognitive task purported to measure "engagement in cognitive reflection." However, a growing body of work has called these assumptions into question (Blacksmith et al., 2019; Patel et al., 2019; Stupple et al., 2017), finding that correct responses on tasks traditionally believed to require analytic reflection often result instead from "smart intuition" (Bago \& De Neys, 2019; Raoelison et al., 2020). Moreover, using both self-report and reaction time data, Littrell and Fugelsang (2021) found that many people who gave higher ratings to pseudoprofound bullshit reported engaging in slower, more error-prone rationalizing while others who were less receptive to bullshit statements reported relying on faster, intuition-like processes. Additionally, Vitriol and Marsh (2021) found that engaging in reflective thinking led to increased, rather than decreased, endorsement of COVID-19 conspiracy theories for many people. Taken together, these findings show not only that some people are better able to detect and dismiss information intuitively, but that others appear to "talk themselves into" believing misleading information by engaging in faulty rationalization. Critically, the results reported here provide clear evidence that actively reflecting on and attempting to explain the details of 
misleading information was not effective for two out of three types of bullshit. This extends previous findings by demonstrating that encouraging people to simply engage in more cognitive reflection, per se, is not the panacea for misinformation that it has been reported to be and that other types of interventions (e.g., "prebunking") may be more effective at reducing the influence of certain types of bullshit (Roozenbeek et al., 2020).

\section{Conclusion}

Is reflection the "best medicine" to treat an epidemic of misinformation? The answer, it seems, is "it depends." Although past research has asserted that receptivity to misinformation is largely explained by a failure to engage in reflective thinking, per se, we found clear evidence against this claim. To the contrary, reflecting on and trying to explain different types of misinformation reduces initial receptivity to pseudo-profound bullshit but does not reduce receptivity to scientific bullshit or fake news headlines. We believe this is because, cognitively, not all misinformation is alike, and this difference can be observed in higher-order processing. This is further supported by evidence of robust guru effects for pseudo-profound and scientific bullshit but not for fake news. Thus, while encouraging the public to be more reflective can certainly be helpful as a general rule, it is not (by itself) a panacea for all forms dubious bullshit and strategies focused on reducing the spread and influence of misinformation would benefit from a more multi-faceted approach. 


\section{References}

Altay, S., Hacquin, A. S., \& Mercier, H. (2020). Why do so few people share fake news? It hurts their reputation. New Media \& Society, 1-22. Advance Online publication. https://doi.org/10.1177/1461444820969893

Bago, B., \& De Neys, W. (2019). The Smart System 1: Evidence for the intuitive nature of correct responding on the bat-and-ball problem. Thinking \& Reasoning, 25(3), 257-299. https://doi.org/10.1080/13546783.2018.1507949

Bago, B., Rand, D. G., \& Pennycook, G. (2020). Fake news, fast and slow: Deliberation reduces belief in false (but not true) news headlines. Journal of Experimental Psychology:

General, 149(8), 1608-1613. http://dx.doi.org/10.1037/xge0000729

Belluz, J. (2018, July 27). Is Gwyneth Paltrow's Goop pseudoscience winning? Vox. Retrieved from https://www.vox.com/science-and-health/2017/7/19/15988180/gwyneth-paltrow-

goop-jade-egg-debunkers

Blacksmith, N., Yang, Y., Behrend, T. S., \& Ruark, G. A. (2019). Assessing the validity of inferences from scores on the cognitive reflection test. Journal of Behavioral Decision Making, 32, 599- 612. https://doi.org/10.1002/bdm.2133

Čavojová, V., Secară, E., Jurkovič, M., \& Šrol, J. (2019). Reception and willingness to share pseudo-profound bullshit and their relation to other epistemically suspect beliefs and cognitive ability in Slovakia and Romania. Applied Cognitive Psychology, 33(2), 299-311. https://doi.org/10.1002/acp.3486 
Crawford, J. T., \& Ruscio, J. (2021). Asking people to explain complex policies does not increase political moderation: Three preregistered failures to closely replicate Fernbach, Rogers, Fox, and Sloman's (2013) findings. Psychological science, 32(4), 611-621. https://doi.org/10.1177\%2F0956797620972367

Condon, D. M., \& Revelle, W. (2014). The international cognitive ability resource: Development and initial validation of a public-domain measure. Intelligence, 43, 52-64. https://doi.org/10.1016/j.intell.2014.01.004

Evans, A. M., Sleegers, W., \& Mlakar, Ž. (2020). Individual differences in receptivity to scientific bullshit. Judgment and Decision-Making, 15(3), 401-412. http://journal.sjdm.org/20/200221/jdm200221.pdf

Fernandez-Duque, D., Evans, J., Christian, C., \& Hodges, S. D. (2015). Superfluous neuroscience information makes explanations of psychological phenomena more appealing. Journal of Cognitive Neuroscience, 27(5), 926-944. https://doi.org/10.1162/jocn_a_00750

Fernbach, P. M., Rogers, T., Fox, C. R., \& Sloman, S. A. (2013). Political extremism is supported by an illusion of understanding. Psychological Science, 24(6), 939-946. https://doi.org/10.1177/0956797612464058

Frey, D., Johnson, E. D., \& De Neys, W. (2018). Individual differences in conflict detection during reasoning. Quarterly Journal of Experimental Psychology, 71(5), 1188-1208. https://doi.org/10.1080/17470218.2017.1313283

Fowler, J. G., Carlson, L., \& Chaudhuri, H. R. (2019). Assessing scientific claims in print ads that promote cosmetics: How consumers perceive cosmeceutical claims. Journal of Advertising Research, 59(4), 466-482. DOI: 10.2501/JAR-2018-048 
Fox, M. (2014, June 17). The 'Dr. Oz Effect': Senators Scold Mehmet Oz For Diet Scams. NBC News. Retrieved from https://www.nbcnews.com/better/diet-fitness/dr-oz-effect-senators$\underline{\text { scold-mehmet-oz-diet-scams-n133226 }}$

Frankfurt, Harry G. 2006. On truth. New York: Alfred A. Knopf.

Gligorić, V., \& Vilotijević, A. (2020). “Who said it?” How contextual information influences perceived profundity of meaningful quotes and pseudo-profound bullshit. Applied Cognitive Psychology, 34(2), 535-542. https://doi.org/10.1002/acp.3626

Goldacre, B. (2010). Bad science: Quacks, hacks, and big pharma flacks. Toronto: McClelland \& Stewart.

Hoogeveen, S., Haaf, J. M., Bulbulia, J., Ross, R. M., McKay, R., Altay, S., ... van Elk, M. (2020). The Einstein effect: Global evidence for scientific source credibility effects and the influence of religiosity. PsyArxiv, https://doi.org/10.31234/osf.io/sf8ez

Ilić, S., \& Damnjanović, K. (2021). The effect of source credibility on bullshit receptivity. Applied Cognitive Psychology, Advance online publication. https://doi.org/10.1002/acp.3852

Johnson, D. R., Murphy, M. P., \& Messer, R. M. (2016). Reflecting on explanatory ability: A mechanism for detecting gaps in causal knowledge. Journal of Experimental Psychology: General, 145(5), 573. https://psycnet.apa.org/doi/10.1037/xge0000161

Litman, L., Robinson, J., \& Abberbock, T. (2016). TurkPrime.com: A versatile crowdsourcing data acquisition platform for the behavioral sciences. Behavior Research Methods, 1 - 10. 
Littrell, S., Risko, E. F., \& Fugelsang, J. A. (2021). "You can't bullshit a bullshitter" (or can you?): Bullshitting frequency predicts receptivity to various types of misleading information. British Journal of Social Psychology, Advance online publication. https://doi.org/10.1111/bjso.12447

Littrell, S., \& Fugelsang, J. (2021). The 'bullshit blind spot': The roles of overconfidence and perceived information processing in bullshit detection. PsyArxiv, https://doi.org/10.31234/osf.io/kbfrz

Lyons, B. A., Montgomery, J. M., Guess, A. M., Nyhan, B., \& Reifler, J. (2021). Overconfidence in news judgments is associated with false news susceptibility. Proceedings of the National Academy of Sciences, 118(23), 1-10. https://doi.org/10.1073/pnas.2019527118

Malhotra, N., Krosnick, J. A., \& Haertel, E. (2007). The Psychometric Properties of the GSS Wordsum Vocabulary Test (GSS Methodology Report No. 111). Chicago: NORC.

Mastrangelo, D. (2021, April 28). Fauci: Joe Rogan's COVID-19 comments 'incorrect'. The Hill. Retrieved from https://thehill.com/homenews/media/550632-fauci-joe-rogans-commentsabout-young-healthy-people-not-needing-a-vaccine

Meyers, E. A., Turpin, M. H., Białek, M., Fugelsang, J. A., \& Koehler, D. J. (2020). Inducing feelings of ignorance makes people more receptive to expert (economist) opinion. Judgment and Decision Making, 15(6), 909-925. http://sjdm.org/journal/20/200615a/jdm200615a.pdf

Mills, C. M., \& Keil, F. C. (2004). Knowing the limits of one's understanding: The development of an awareness of an illusion of explanatory depth. Journal of Experimental Child Psychology, 87(1), 1-32. https://doi.org/10.1016/j.jecp.2003.09.003 
Nadarevic, L., Reber, R., Helmecke, A. J., \& Köse, D. (2020). Perceived truth of statements and simulated social media postings: an experimental investigation of source credibility, repeated exposure, and presentation format. Cognitive Research: Principles and Implications, 5(1), 1-16. https://doi.org/10.1186/s41235-020-00251-4

Patel, N., Baker, S. G., \& Scherer, L. D. (2019). Evaluating the cognitive reflection test as a measure of intuition/reflection, numeracy, and insight problem solving, and the implications for understanding real-world judgments and beliefs. Journal of Experimental Psychology: General, 148(12), 2129-2153. http://dx.doi.org/10.1037/xge0000592

Pennycook, G., Cheyne, J. A., Barr, N., Koehler, D. J., \& Fugelsang, J. A. (2015a). On the reception and detection of pseudo-profound bullshit. Judgment and Decision Making, 10(6), 549-563. http://journal.sjdm.org/15/15923a/jdm15923a.pdf

Pennycook, G., Epstein, Z., Mosleh, M., Arechar, A. A., Eckles, D., \& Rand, D. G. (2021). Shifting attention to accuracy can reduce misinformation online. Nature, 592(7855), 590595. https://doi.org/10.1038/s41586-021-03344-2

Pennycook, G., Fugelsang, J. A., \& Koehler, D. J. (2015b). What makes us think? A three-stage dual-process model of analytic engagement. Cognitive Psychology, 80, 34-72. https://doi.org/10.1016/j.cogpsych.2015.05.001

Pennycook, G., \& Rand, D. G. (2019). Lazy, not biased: Susceptibility to partisan fake news is better explained by lack of reasoning than by motivated reasoning. Cognition, 188, 39-50. https://doi.org/10.1016/j.cognition.2018.06.011

Pennycook, G., \& Rand, D. G. (2020). Who falls for fake news? The roles of bullshit receptivity, overclaiming, familiarity, and analytic thinking. Journal of Personality, 88(2), 185-200. https://doi.org/10.1111/jopy.12476 
Pew Research Center (2016). Many Americans Believe Fake News Is Sowing Confusion. Pew Research Center, Washington, D.C.

https://www.pewresearch.org/journalism/2016/12/15/many-americans-believe-fake-news-issowing-confusion/

Rabb, N., Fernbach, P. M., \& Sloman, S. A. (2019). Individual representation in a community of knowledge. Trends in Cognitive Sciences, 23(10), 891-902. https://doi.org/10.1016/j.tics.2019.07.011

Raoelison, M., Thompson, V. A., \& De Neys, W. (2020). The smart intuitor: Cognitive capacity predicts intuitive rather than deliberate thinking. Cognition, 204, 104381. https://doi.org/10.1016/j.cognition.2020.104381

Reisch, G. A. (2006). “The pragmatics of bullshit, intelligently designed.” In G. L. Hardcastle \& G. A. Reisch (Eds.), Bullshit and philosophy: Guaranteed to get perfect results every time (pp. 33-47). Chicago: Open Court.

Rhodes, R. E., Rodriguez, F., \& Shah, P. (2014). Explaining the alluring influence of neuroscience information on scientific reasoning. Journal of Experimental Psychology: Learning, Memory, and Cognition, 40(5), 1432-1440. https://doi.org/10.1037/a0036844

Roozenbeek, J., van der Linden, S., \& Nygren, T. (2020). Prebunking interventions based on "inoculation" theory can reduce susceptibility to misinformation across cultures. Harvard Kennedy School (HKS) Misinformation Review. https://doi.org/10.37016//mr-2020-008

Rozenblit, L., \& Keil, F. (2002). The misunderstood limits of folk science: An illusion of explanatory depth. Cognitive Science, 26(5), 521-562. https://doi.org/10.1207/s15516709 $\operatorname{cog} 2605 \_1$ 
Salovich, N. A., \& Rapp, D. N. (2021). Misinformed and unaware? Metacognition and the influence of inaccurate information. Journal of Experimental Psychology: Learning, Memory, and Cognition, 47(4), 608-624. https://doi.org/10.1037/xlm0000977

Simpson, S. (2019). Fake News: A global epidemic, vast majority (86\%) of online global citizens have been exposed to it. Ipsos. https://www.ipsos.com/en-us/news-polls/cigi-fake-news-global-epidemic

Sloman, S. A., \& Rabb, N. (2016). Your understanding is my understanding: Evidence for a community of knowledge. Psychological Science, 27(11), 1451-1460. https://doi.org/10.1177/0956797616662271

Sperber, D. (2010). The guru effect. Review of philosophy and psychology, 1(4), 583-592. https://doi.org/10.1007/s13164-010-0025-0

Spicer, A. (2020). Playing the bullshit game: How empty and misleading communication takes over organizations. Organization Theory, 1(1), 1-26. https://doi.org/10.1177\%2F2631787720929704

Stupple, E. J., Pitchford, M., Ball, L. J., Hunt, T. E., \& Steel, R. (2017). Slower is not always better: Response-time evidence clarifies the limited role of miserly information processing in the Cognitive Reflection Test. PloS One, 12(11), e0186404. https://doi.org/10.1371/journal.pone.0186404

The Pearson Institute for the Study and Resolution of Global Conflicts. (2021). The American public views the spread of misinformation as a major problem. Pearson Institute for the Study and Resolution of Global Conflicts, The Associated Press-NORC Center for Public Affairs Research. https://apnorc.org/projects/the-american-public-views-the-spread-of$\underline{\text { misinformation-as-a-major-problem/ }}$ 
Thorndike, R. L. (1942). Two screening tests of verbal intelligence. Journal of Applied Psychology, 26(2), 128-135.

Tsang, S. J. (2020). Motivated fake news perception: The impact of news sources and policy support on audiences' assessment of news fakeness. Journalism \& Mass Communication Quarterly, 1077699020952129. https://doi.org/10.1177\%2F1077699020952129 14(6), 658-670. http://journal.sjdm.org/19/190712/jdm190712.html

Vitriol, J. A., \& Marsh, J. K. (2018). The illusion of explanatory depth and endorsement of conspiracy beliefs. European Journal of Social Psychology, 48(7), 955-969. https://doi.org/10.1002/ejsp.2504

Vitriol, J. A., \& Marsh, J. K. (2021). A pandemic of misbelief: How beliefs promote or undermine COVID-19 mitigation. Frontiers in Political Science, 3(54), 648082. https://doi.org/10.3389/fpos.2021.648082

Vosoughi, S., Roy, D., \& Aral, S. (2018). The spread of true and false news online. Science, 359(6380), 1146-1151. https://www.science.org/doi/10.1126/science.aap9559 